\title{
Application of advanced InSAR techniques to detect vertical and horizontal displacements
}

J. Morgan TRE Canada Inc., Canada

S. Raval The University of New South Wales, Australia

B. Macdonald TRE Canada Inc., Canada

G. Falorni TRE Canada Inc., Canada

J. Iannacone University of Modena and Reggio Emilia, Italy

\begin{abstract}
The monitoring of surface subsidence is an important aspect in many underground mines. There are various ground-based methods that can be used for deformation monitoring, including optical levelling, GPS, and tiltmeters. This study proposes the use of satellite-based InSAR for the monitoring of surface movement over the Metropolitan Mine, an underground coal mine located in the Southern Coalfields of New South Wales, Australia where ground subsidence has been documented. An advanced multi-image InSAR approach, characterised by a high density of measurement points and millimetre precision, is applied to illustrate how results provide an overview of surface displacement dynamics before, during and after active mining. Two stacks of ENVISAT radar imagery (87 total images) acquired between June 2006 and August 2010 were analysed with the SqueeSAR ${ }^{T M}$ algorithm to reconstruct ground movement patterns during this period. Movements were assessed on a 35-day interval (the revisitation frequency of the ENVISAT satellite), and a time series of deformation was generated for every measurement point. The use of two image stacks acquired from different viewing geometries allowed both the vertical and east-west components of ground movement over this site to be determined. Results illustrate the surface-level impact of underground mining by quantifying the spatial extent and timing of surface movement. The precision of the InSAR data were briefly assessed by comparing results with ground-based GPS survey measurements. While the timing and direction of movements were similar, the comparison was limited by the lack of both spatial and temporal overlap of the data sets. The use of a radar satellite with a higher temporal frequency is recommended for future monitoring of this site.
\end{abstract}

\section{Introduction}

The Southern Coalfield of New South Wales in Australia contains extensive regions of valuable coal deposits. Many of these coal resources are vulnerable to mining-induced subsidence, which may result in operational liability and/or ecological impacts on the ground surface. The ability to track and monitor these surface-level impacts caused by underground mining activities is a key element in the development of sustainable mining practices and concepts. However, conventional monitoring methods (i.e. ground-based) can be labour intensive, time-consuming and costly when requiring detailed spatial coverage over large areas. Furthermore, field surveys can be challenging to implement in variable terrain and in potentially unsafe or restricted access conditions.

Ground-based techniques have been used in several cases to gather detailed subsidence data over localised areas, or hot spots. For instance, Strata Control Technology (SCT), a company engaged in providing solutions to mining geotechnical and strata control problems, has measured ground movements via three dimensional surveying at the Baal Bone, Clarence and Springvale Collieries (Mills, 2001). At Illawarra Coal, a GPS network of control points extending beyond the mining region was used to identify possible horizontal ground movements (Anderson et al., 2007). This system is also in use at the Ulan Coal Mine and provides accurate measurements of horizontal ground movements around the installed GPS stations (Mills et al., 
2011). However, while ground survey techniques can provide a high level of point source detail which can be interpolated over small areas, it is not possible to maintain the same data sampling density over large areas.

Satellite-based InSAR techniques can detect ground deformation to millimetre scale accuracy over large areas. Several studies have successfully measured mining induced ground deformation using differential radar interferometry (DInSAR) techniques (Carnec and Delacourt, 2000; Chang et al., 2008; Gao et al., 2005; Jarosz and Wanke, 2003; Jarosz et al., 2008; Ng et al., 2008; Perski et al., 2009; Raucoules et al., 2008; Wegmüller et al., 2004; Yue et al., 2011). These, however, have mainly focused on measuring vertical movement, while ground subsidence over coal mines also has a strong horizontal component. Furthermore, the direction of mining with respect to ground slope also has a significant impact on ground movement (Kay, 1991).

This project aims to use advanced InSAR techniques to identify the extent, direction, and timing of historic surface subsidence over the Metropolitan Mine in New South Wales induced by longwall mining within the Illawarra coal measure. Two archived radar data sets were analysed in combination in order to extract vertical and east-west horizontal movement occurring between 2006 and 2010 during a period of active operations at the Metropolitan Mine. The integration of InSAR data with ground-based monitoring systems is discussed, and results are compared to an existing set of GPS surveys. The use of InSAR for underground mine monitoring, particularly when this type of information is integrated with conventional surveying approaches, demonstrates how this technology can improve subsidence monitoring. Recommendations for future InSAR monitoring of the Metropolitan Mine are also provided.

\section{$2 \quad$ Methodology}

\subsection{Radar satellite data}

Radar satellites have been providing commercially available data since 1992 . These satellites have active sensors that create and direct a pulse of microwave energy towards the earth and measure the returned signal. This allows for day or night imaging and very little interference from cloud cover or other atmospheric conditions. Radar sensors use a complex signal, which means the amplitude and phase value of each pixel is recorded and it is the phase signal that makes interferometry possible.

\subsection{Radar interferometry}

Imaging radars are time based systems that measure the time it takes for a pulse to hit a target and return to the satellite. These pulses record both the amplitude (strength) of radar returns, and the phase (wave cycle). When the satellite takes a new image from the same orbit geometry in the future, the process is repeated giving a new amplitude and phase history. Changes in the signal phase values (representing small changes in the signal path length) are analysed over stacks of satellite data, and changes induced by motion are isolated. As an image stack grows over time, a sufficient record of phase information can be obtained to provide millimetre accuracy of measurements.

Advanced forms of InSAR process a large number of radar images to determine the displacement of radar targets over time. Stable targets can be naturally occurring features such as rock outcrops, or man-made objects such as buildings and artificial reflectors (referred to as Permanent or Persistent Scatterers) that maximise radar return strength and coherence (Ferretti et al., 2001, Ferretti et al., 2007). The processing of a long series of radar images (at least fifteen) introduces a time factor that allows the motion history of a radar target to be observed (including non-linear motion), and increases measurement precision to millimetre level accuracy. This precision is achieved by applying advanced statistical algorithms to remove atmospheric noise and orbital effects from the data. The SqueeSAR ${ }^{\mathrm{TM}}$ algorithm presents the unique feature of processing the weaker signals from spatially distributed targets covering several pixels (referred to as Distributed Scatterers), which significantly increases the density of measurement points in non-urban areas (Ferretti et al., 2011a). These distributed scatterers are large homogeneous areas of ground surface such as 
fields, or sparsely vegetated areas (DS - Figure 1). As a result, this approach works well over the varied surface conditions found over underground mine sites such as the Metropolitan Mine.
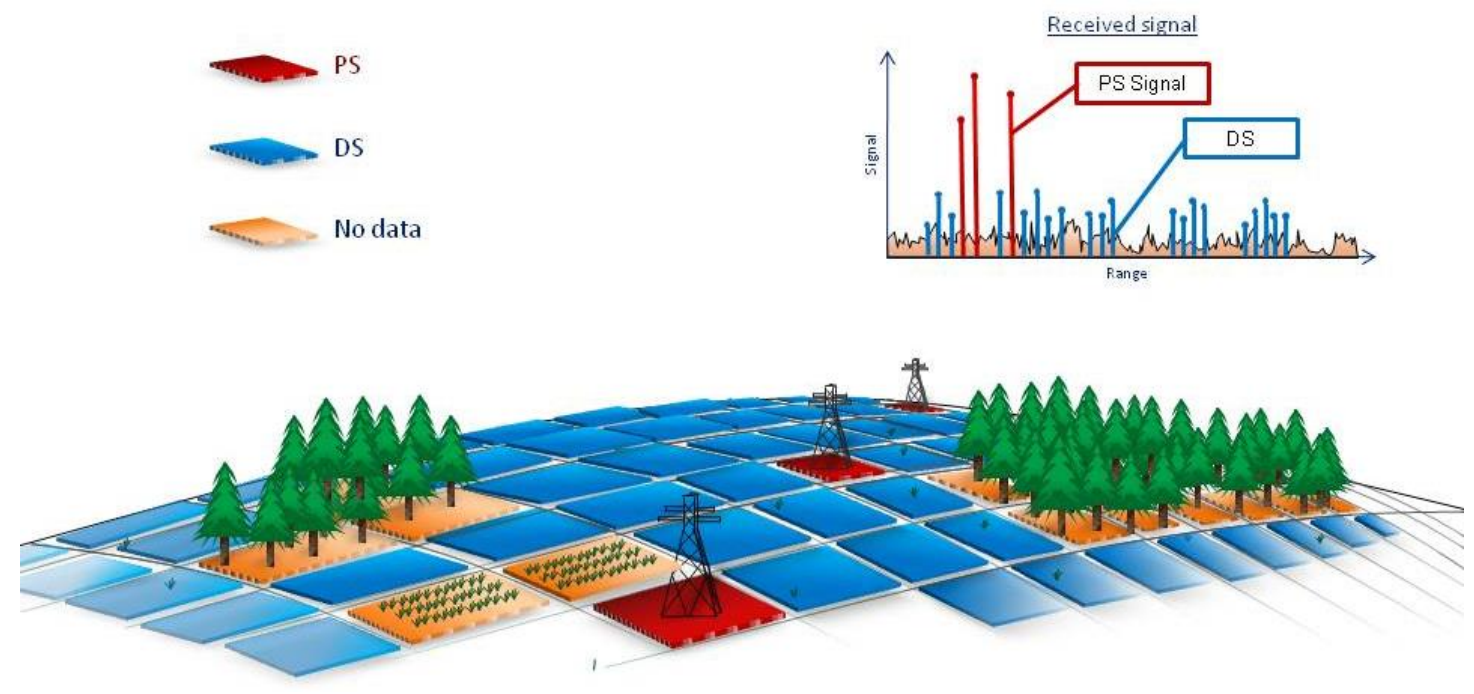

Figure 1 Illustration of the identification of permanent scatterers (PS) and distributed scatterers (DS) with the SqueeSAR ${ }^{\mathrm{TM}}$ algorithm

\subsection{Movement decomposition}

The displacements measured by radar satellites are one-dimensional, and are called line of sight (LOS) measurements. If an object on the ground has moved, the satellite will observe that the distance between itself and the object either increases or decreases, depending on the direction of movement. LOS measurements can be challenging to interpret since these measurements often contain both vertical and horizontal components of movement. However, by viewing the same area from the opposite viewing geometry, such as from ascending (satellites travelling from south to north) and descending orbits (satellite travelling from north to south), information about multi-directional ground movement can be obtained. This is accomplished by combining the LOS measurements into a regular grid of points from which the true vertical and east-west horizontal vectors can be extrapolated using basic vector geometry. All radar satellites travel along a near-polar orbital path and acquire images with a right-looking viewing geometry (radar beam looks eastward or westward), meaning satellites are sensitive to movement in the vertical and east-west direction, but have limited sensitivity in the direction of travel (north-south).

The extraction of multi-directional movement is beneficial as this information can contribute to the identification of movement patterns and/or failure mechanisms over large areas (i.e. entire mine sites). This is achieved by providing detailed overviews of ground movement dynamics using InSAR data to isolate the specific locations and timing of motion onset, as well as periods of movement acceleration and deceleration. Vertical and horizontal components are necessary for fault characterisation, which may be incomplete with the acquisition of one orbital geometry. Complex subsidence patterns, such as valley closure, valley floor uplift and other movement trends modified by surface terrain can also be identified from the analysis of multiple geometries. This can be particularly relevant to mining operations carried out in locations of irregular surface topography where single observation geometry may not cover all regions.

\subsection{InSAR and ground-based monitoring}

The use of InSAR for ground deformation monitoring is fairly well established in the fields of landslide and natural hazard monitoring, and has also been widely used to map the surface expression of faults and tectonic motion (Colesanti et al., 2003; Tamburini et al., 2013). InSAR has also been used extensively for monitoring of hydrocarbon reservoirs, fields undergoing enhanced oil recovery, as well as carbon capture and storage (Ferretti et al., 2011b; Klemm et al., 2010). As a result, the verification and integration of InSAR with ground-based monitoring systems is fairly well established (Ferretti et al., 2007). 
One of the main considerations to make when integrating InSAR and ground-based systems, is the calibration of the two systems, as InSAR measurements are differential (meaning displacement is measured compared to a reference point that is assumed to be stable) and identified points do not always coincide with the locations of ground-based instruments. The ideal approach would be to install artificial reflectors (ARs), which are ground-based structures that provide guaranteed reflections of the radar signal, in conjunction with a GPS station/survey location in order to provide the best measurement control for integrated monitoring. However, in the case of historical comparisons such as over the Metropolitan site, results must be calibrated between two or more independent data sets. For instance, GPS and InSAR results were linked over the city of Venice by calculating a plane of differences and using this plane to tie displacement results to an absolute reference frame defined by the GPS (Bock et al., 2012). Another study re-projected data from a GPS network to the same viewing geometry of the InSAR data for the monitoring of an unstable slope over Lake Sarez and the Usoi dam in Tajikistan (Droz et al., 2008).

\section{Study site and data}

The Metropolitan Mine is an underground coal mine located in the Southern Coalfields of New South Wales, Australia, near Helensburgh (Figure 2). The Southern Coalfield is one of five coalfields within the Sydney-Gunnedah basin. The main coal measure of the Southern Coalfield is the Illawarra coal measure which has four coal seams, namely the Bulli Seam $(1-4 \mathrm{~m})$, the Balgownie Seam $(\sim 1.5 \mathrm{~m})$, the Wongawilli Seam $(6-15 \mathrm{~m})$ and Tongarra Seam $(1.2-6.7 \mathrm{~m})$. The Illawarra coal measure is overlain by the Narrabeen Group (late Permian late Triassic) which is mainly composed of sandstone, claystone and shale. At the Metropolitan Mine, the thickness of the Narrabeen group is about $300 \mathrm{~m}$ within its main formation, while the Bulgo Sandstone is about $200 \mathrm{~m}$ thick. The Narrabeen Group is overlain by Middle Triassic quartz sandstone, and Hawkesbury Sandstone which is the upper formation extending over most of the area. Surface topography of the area ranges from 70 to $120 \mathrm{~m}$ above the river level, which results in a typical overburden depth range of 400 to $470 \mathrm{~m}$, while occasionally reaching a maximum of about $520 \mathrm{~m}$. 


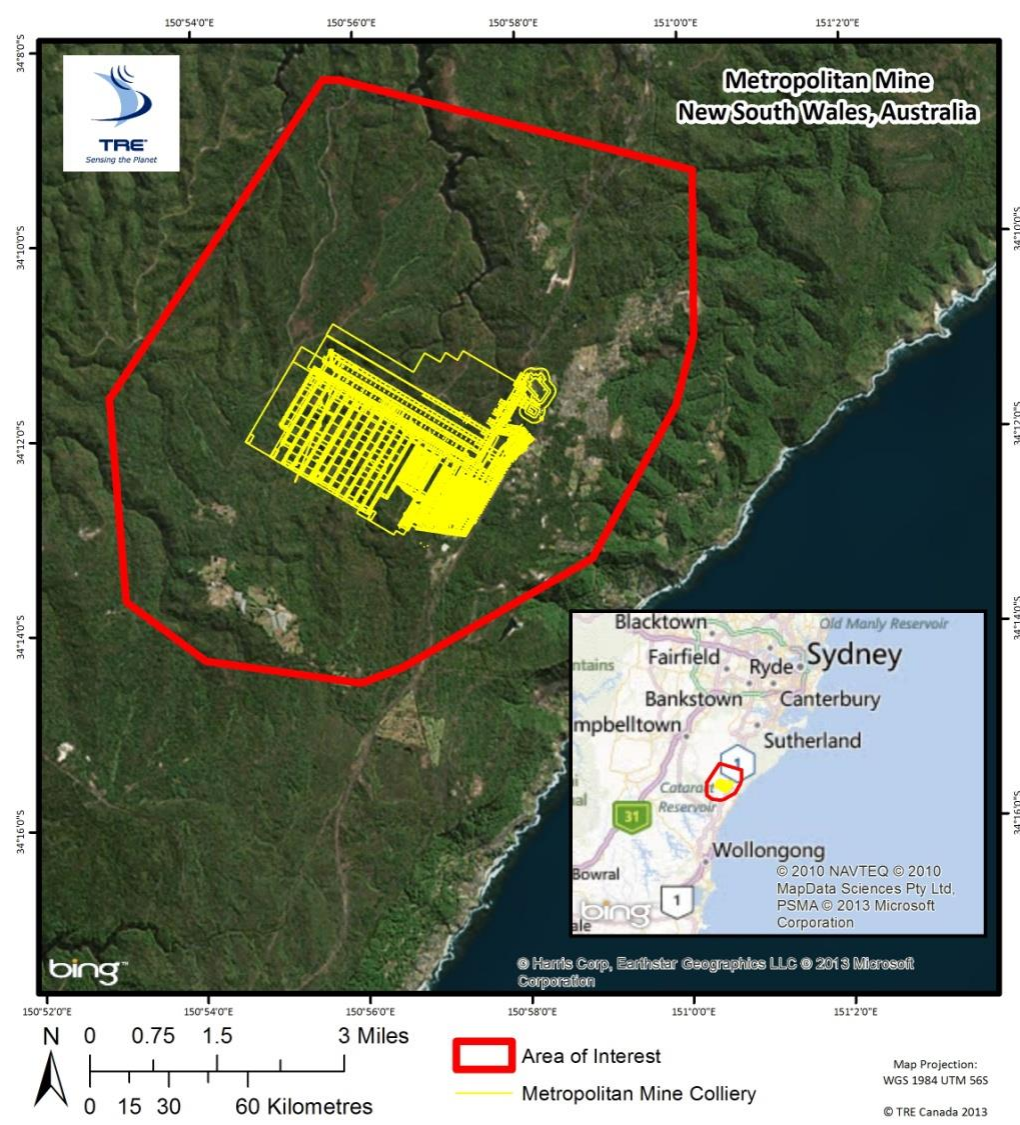

Figure 2 Overview of the Metropolitan Mine site, and the area of interest over which data processing was conducted

Ground deformation associated with subsidence linked to underground mining operations has been identified and monitored using GPS. Uplift-effects as well as valley closure (two sides of a valley move horizontally towards the valley centre line), have also been documented in this area. The Metropolitan Mine has established a subsidence monitoring program to validate the predictions of mining induced deformation as well as to generate data to improve the understanding of various factors contributing to ground movement. Currently this program includes subsidence parameter monitoring (i.e. the actual movement of the ground surface) and subsidence impact monitoring (e.g. surface cracking) through several ground survey lines and observation points. Valley closure and ground subsidence within the area have resulted in shallow cracking in the bedrock along Waratah Rivulet which has increased their hydraulic conductivity and affected the persistence of retained pools (Mills, 2011).

Two stacks of archive ENVISAT radar imagery were used for the InSAR analysis. The two data sets consisted of 44 images acquired along an ascending orbit (Track 381) and 43 images acquired on a descending orbit (Track 402). Both data sets cover a time period extending from June 2006 to September 2010, and were acquired on a 35-day repeat interval.

\section{$4 \quad$ Results}

\subsection{Line-of-sight movement}

The application of the SqueeSAR approach resulted in measurement point densities of 191 and 135 points per square kilometre for the ascending and descending data sets, respectively. A large area of subsidence was observed directly over the areas of active operations at the Metropolitan Mine, with displacement rates up to $-34 \mathrm{~mm} /$ year detected along the satellite LOS, or viewing angle of the satellite (Figure 3 ). Note 
that Figure 3 shows movement saturated at $\pm 10 \mathrm{~mm} /$ year to adequately represent and characterise the subsidence feature.

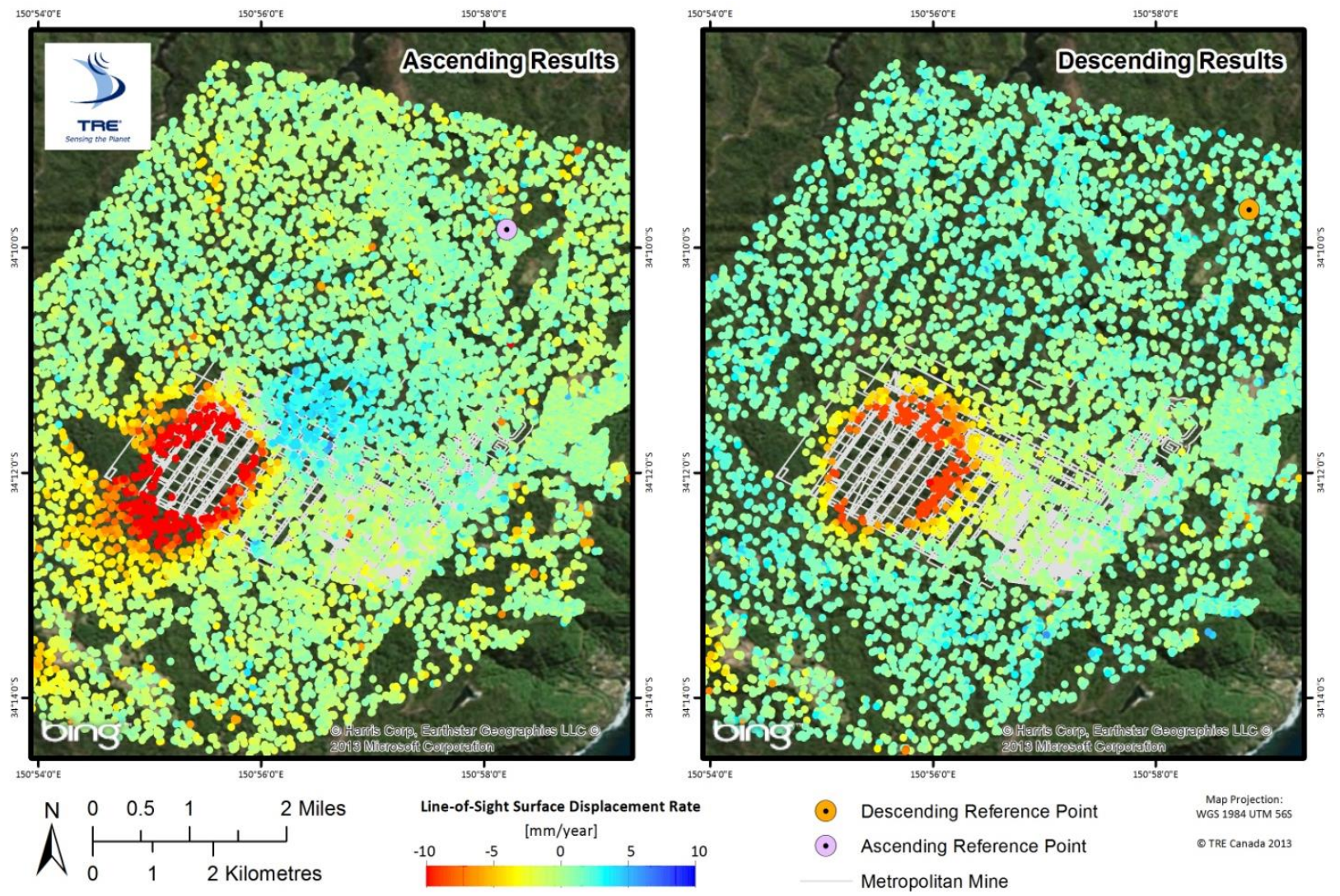

Figure 3 Measured surface displacement rates along the satellites line-of-sight for the ascending (left panel); and descending (right panel), expressed in millimetres per year (mm/year)

While the spatial coverage of measurement points was good throughout most of the area of interest (AOI), there is a gap in the results within the center of the subsidence feature. This is due to the low temporal sampling rate of the historic ENVISAT radar data (a maximum of one new image acquired every 35 days), combined with the rapid and non-linear motion occurring in this area. These two factors contribute to the loss of a coherent radar signal over time. While other SAR-based approaches can be used to track faster types of movement (such as speckle tracking), these methods could not be employed over this site due to a lack of PS type, point-source measurement points.

As the surface characteristics within this gap do not appear to change significantly from the surrounding area, it is likely that complete SqueeSAR data coverage would be possible over this area in the future with the use of satellites with higher revisit frequency, such as the Cosmo-SkyMed constellation of satellites (capable of 16- or 8-day revisits, or even every four days on average) or the TerraSAR-X satellite (one new image every 11 days). The installation of ARs could also be used to provide measurement points over critical areas of rapid movement.

\subsection{Vertical and east-west movement}

The use of different viewing geometries (ascending and descending) provides displacement information from different perspectives and can be combined to characterise multi-directional ground movement (Figure 4). Vertical displacement rates confirm the presence of an area of subsidence over active operations, with up to $-95 \mathrm{~mm}$ of cumulative movement recorded over the four year time period. East-west horizontal displacement results show a clear pattern of horizontal movement towards the central portion of the region of subsidence. Cumulative horizontal movement up to $65 \mathrm{~mm}$ was observed in 
the eastern direction (along the southwest portion of the subsidence feature), and $109 \mathrm{~mm}$ in a westward direction (at the eastern edge of the subsidence feature).

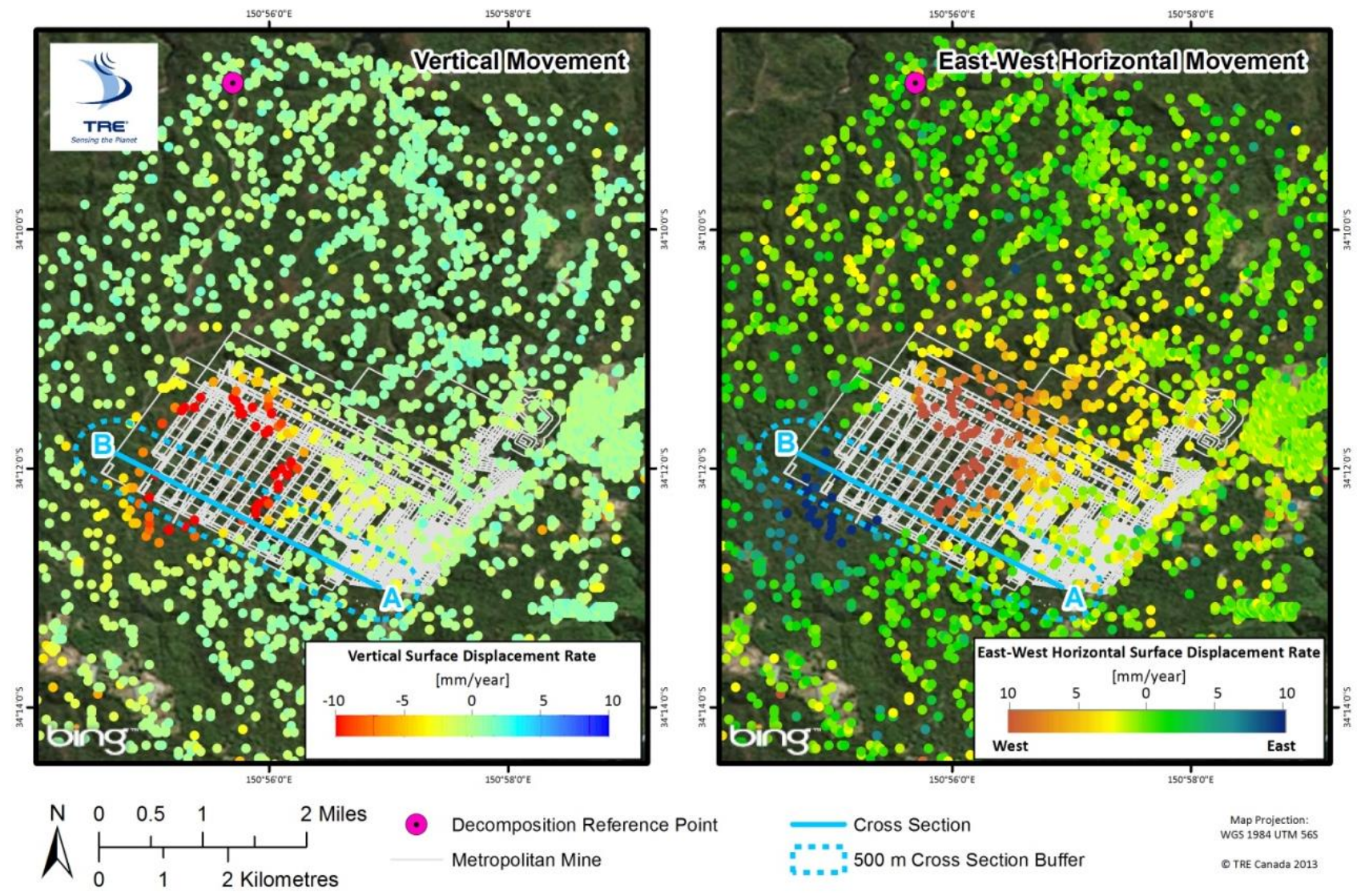

Figure 4 Measured surface displacement rates for the decomposed vertical (left panel); and east-west horizontal (right panel), expressed in millimetres per year ( $\mathrm{mm} /$ year)

Surface profile cross-sections represent the evolution of horizontal profiles of the ground surface over time, with each individual profile line corresponding to ground displacement measured from one image compared to the reference image (usually the first image of the data stack). Surface profiles were created using both the vertical and east-west horizontal results to illustrate different movement patterns identified along these two directions of motion (Figures 5 and 6 ). These profiles were produced using a weighted average of all the measurement points identified within a $500 \mathrm{~m}$ buffer of the profile trace. Note that the surface profile highlighted in red corresponds to the last image in the data stack.

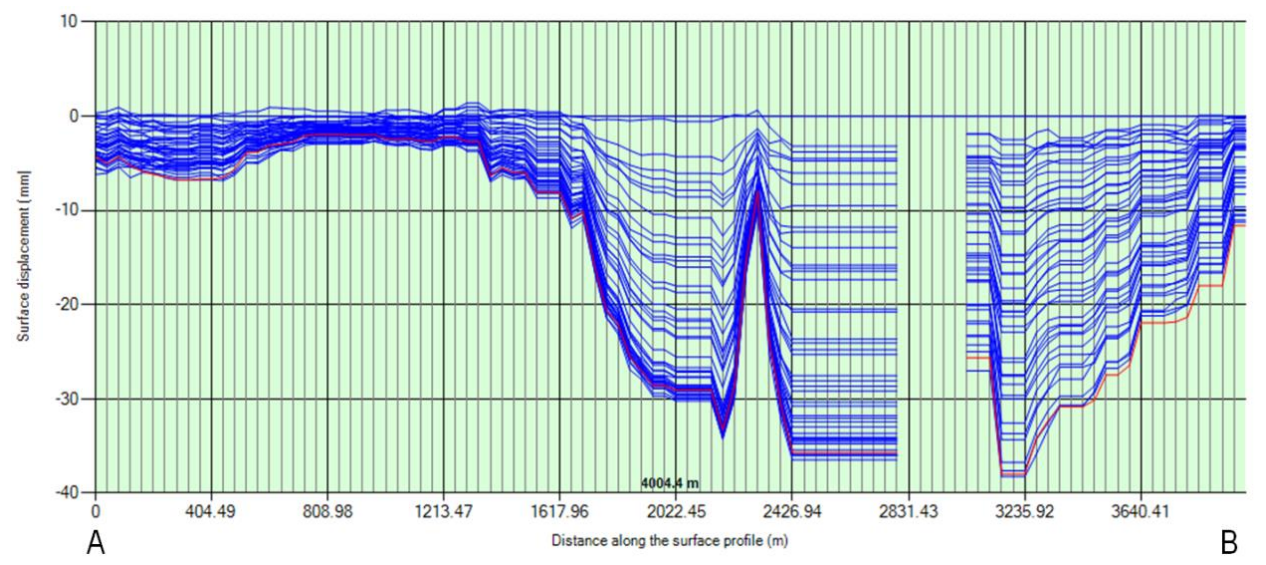

Figure 5 Changes to the surface profile in the vertical direction occurring over the cross-section indicated in Figure 4 


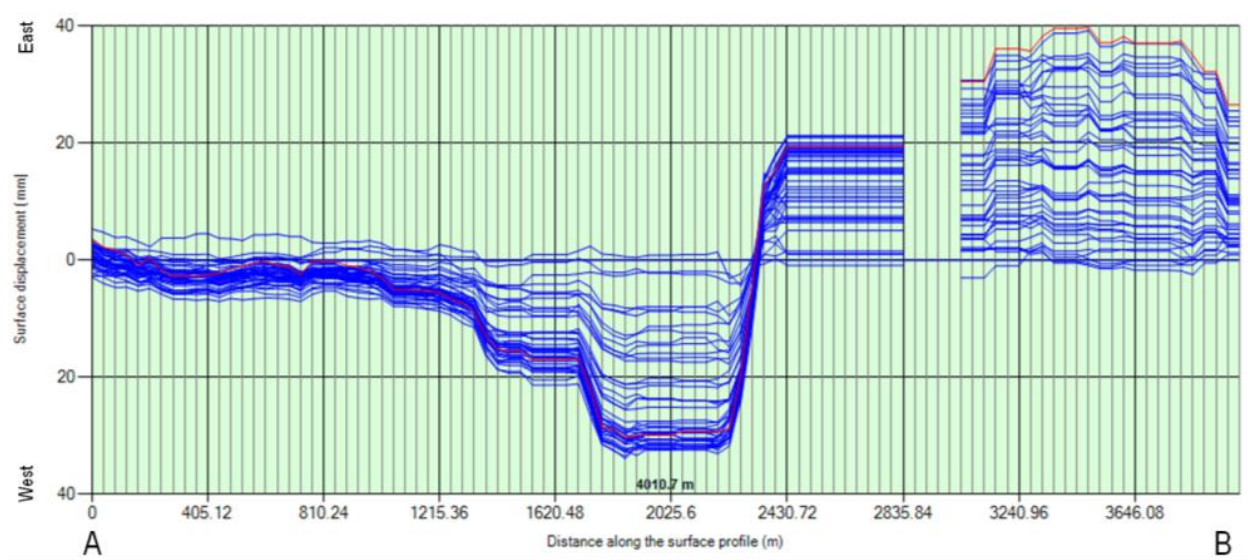

Figure 6 Changes to the surface profile in the east-west horizontal direction occurring over the cross-section indicated in Figure 4

\subsection{Integration with ground survey data}

Displacement has been monitored along four different survey lines located over the Metropolitan Mine using static GPS surveys (Leica 1200 GPS). These survey lines are controlled from two fixed, coordinated stations. Surveys were conducted from each GPS control location in order to synchronise levelling stations which were then used to match subsidence markers. Traverse work was carried out with a $1^{\prime}$ total station (Leica 1200) with an EDM accuracy of $\pm 1.5+3 \mathrm{ppm}$. Due to the variable terrain of this area, the majority of this survey work was conducted from valleys with a limited view of the sky. As a result, the precision achieved by the GPS under these conditions was observed to be $\pm 8 \mathrm{~mm}$ for position and $\pm 15 \mathrm{~mm}$ for height (Helensburgh Coal Pty Ltd).

When the GPS survey data and InSAR results are combined, results provide a more complete overview of ground subsidence dynamics occurring in this area as compared to either data set considered alone. While a gap is still present over part of the mine undergoing active operations, survey lines $E$ and $F$ provide information where InSAR measurement points were not identified (Figure 7). A single profile of cumulative movement identified between 2006 and 2010 (white dashed line in Figure 7) can be used to illustrate how the simple combination of these two data sets may be useful for modelling movement trends in this area (Figure 8). 


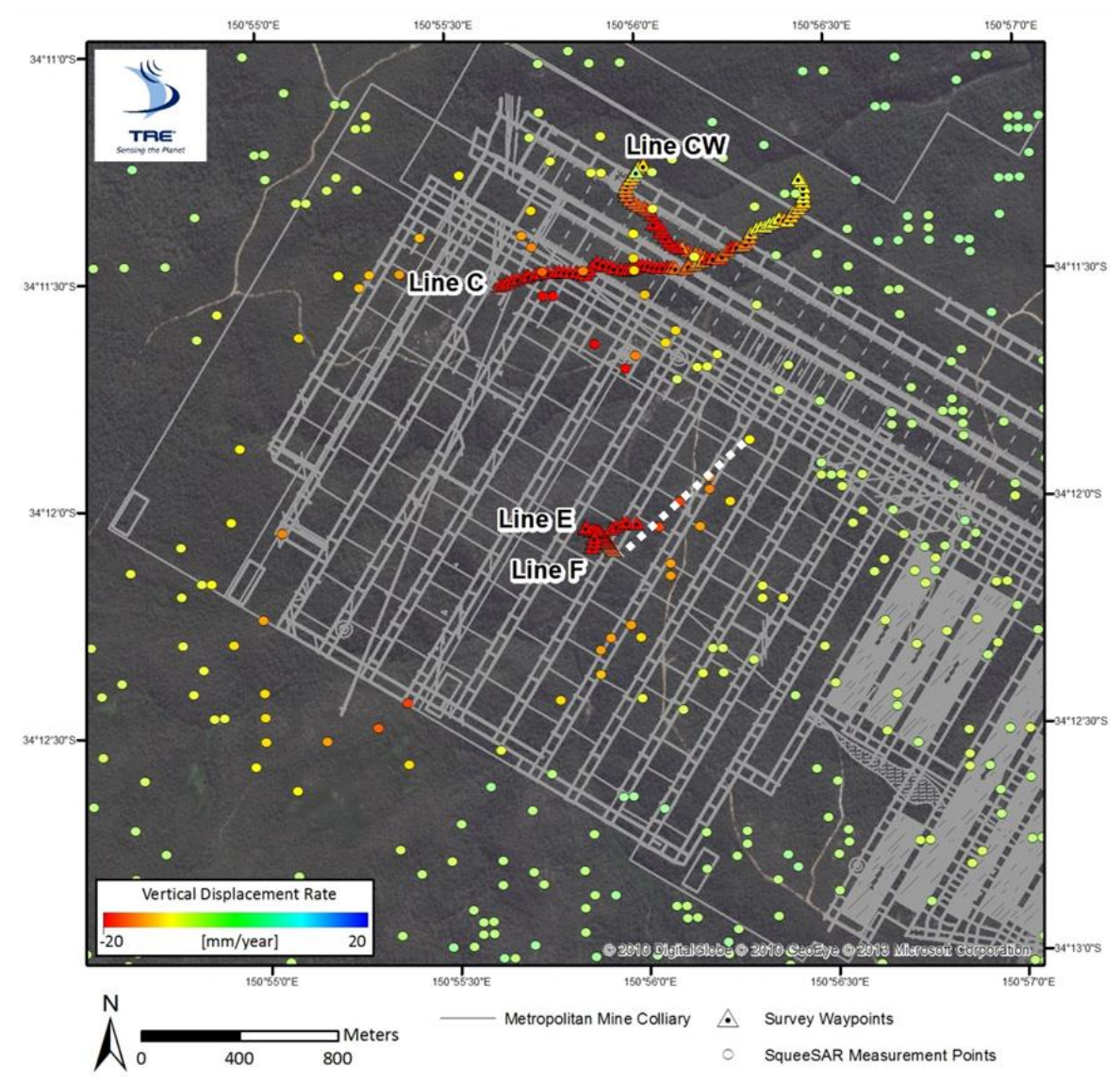

Figure 7 The location of four ground-based survey lines, overlain with the vertical displacement results and the location of the underground Metropolitan Mine

\section{Cumulative subsidence measured across the boundary between InSAR measurement points and the survey data}

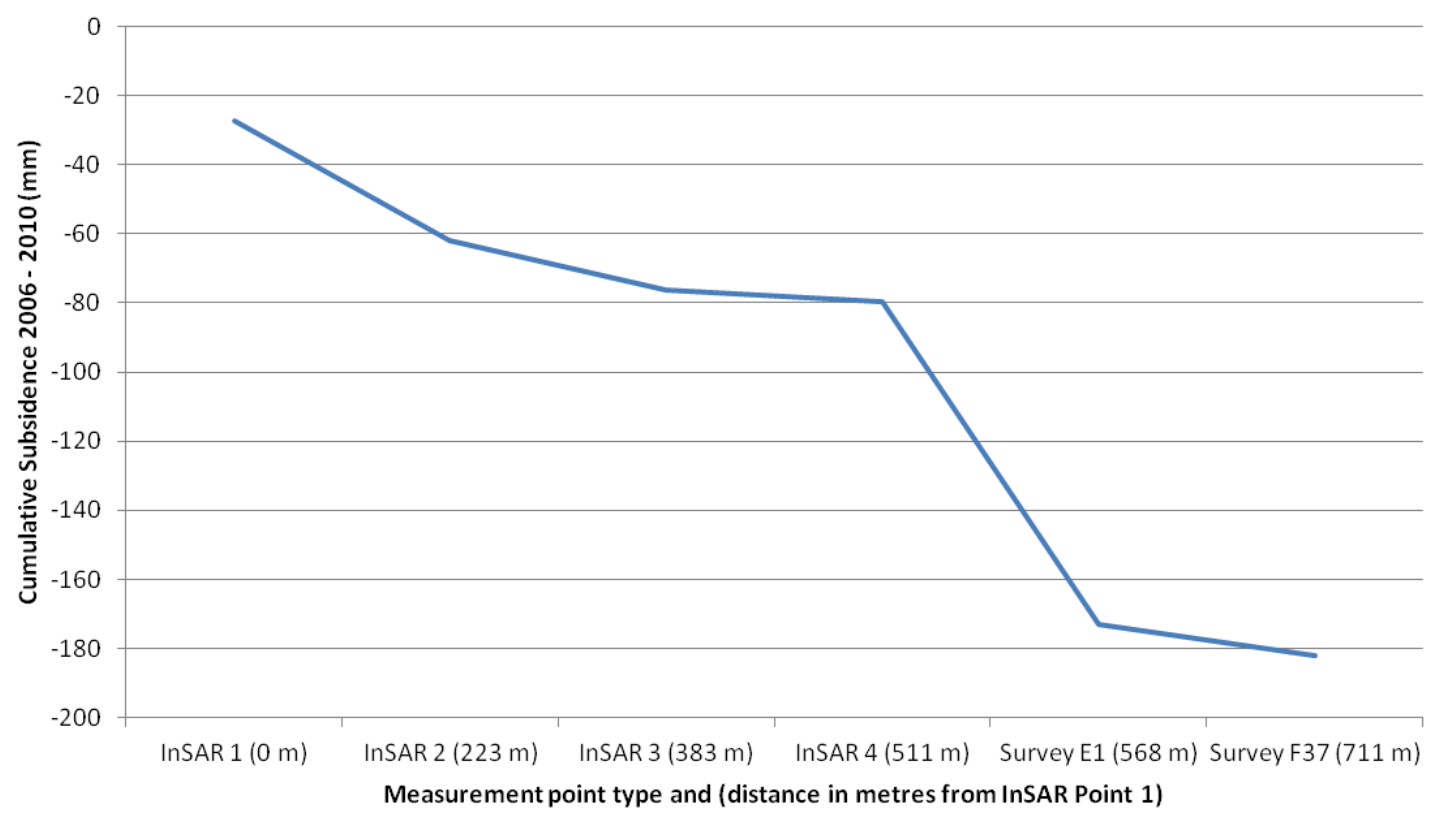

Figure 8 Cumulative movement identified along the profile (dashed white line) shown in Figure 7 
In general, the GPS measurements are in agreement with the InSAR results; however, the lack of spatial overlap between the SqueeSAR points and Line E and F (survey conducted between 2003 and 2009), as well as the lack of temporal overlap between the SqueeSAR points and Line C and CW (survey conducted between 2010 and 2011), prevented a thorough cross-calibration of these two data sets from being carried out (Figure 7). Additional considerations are listed below:

1. Movement occurring over the mine was extremely rapid, non-linear and often sudden (on the scale of tens of centimetres and/or metres). The long revisit time of the ENVISAT satellite (one image every 35 days) limits the extent to which fast, irregular movement can be identified with InSAR, and as a result, subsidence rates were under-estimated along the borders of the subsidence feature identified over the mine.

2. Surface characteristics of this site are not conducive (i.e. vegetated, non-urban) to the identification of Permanent Scatterers or highly reflective features which could be utilised to apply other SAR techniques capable of measuring much larger movements (such as speckle tracking, which can detect movement on the scale of metres).

3. Displacement occurring over this area varies rapidly over short distances (i.e. $60 \mathrm{~cm}$ over a distance less than $250 \mathrm{~m}$ based upon the field survey results). Large changes in movement over short distances are hampered by the low spatial resolution $(20 \times 5 \mathrm{~m}$ pixels) of the ENVISAT satellite. The resolution of current radar satellites $(3 \times 3 \mathrm{~m}$ for Cosmo-SkyMed and TerraSAR-X) would provide a higher density of measurement points, which would allow better tracking of strong differential motion. However, for localised areas where large movement is expected, it may be beneficial to supplement InSAR monitoring with ground-based approaches.

In the case of ongoing monitoring campaigns with InSAR over the Metropolitan Mine, ARs can be installed in order to integrate the two monitoring approaches and provide a point of calibration. As this study was a historic analysis, any comparison was limited by the availability of the historic survey data collection and the InSAR coverage.

\subsection{Comparison with mining operations}

The timing of the movement events were found to correspond with known mine operations, with an onset of movement observed in relation to the initiation of mine activities (expansion), as well as ground stabilisation or mild ground compaction over areas where operations concluded. Trends between the magnitude of the subsidence rates detected with InSAR and the date of the mining activities were examined by averaging displacement rates of all measurement points identified over each of the longwall goafs in the Metropolitan Mine (Table 1). In general, the more recent the mining activity, the higher the subsidence rates.

Results indicated that the ground surface over the oldest portions of the Metropolitan Mine were still experiencing mild subsidence as of 2010. In addition to ongoing settlement of this area over time (stabilisation), these movement patterns may also be influenced by the close proximity of more recent mining operations in 2010 along the edge of the oldest longwalls (90 degrees north of the original mine layout). As the InSAR results only extend to September 2010, a full analysis and comparison of these results to mining operations could not be undertaken. It is also important to note that the low subsidence rates identified over this area are approaching the confidence limits of the InSAR results $( \pm 1 \mathrm{~mm})$. The extent to which future operations will influence surface subsidence over the old mined area is unknown, and further analysis is required. 
Table 1 Summary of longwall mining dates and the average displacement rate in $\mathrm{mm} / y e a r$ identified over each longwall between 2006 and 2010

\begin{tabular}{cccccc}
\hline Longwall & Start Date & End Date & $\begin{array}{c}\text { Average Rate } \\
\text { (Vertical) }\end{array}$ & $\begin{array}{c}\text { Average Rate } \\
\text { (Ascending LOS) }\end{array}$ & $\begin{array}{c}\text { Average Rate } \\
\text { (Descending LOS) }\end{array}$ \\
\hline LW1 & 31 Jul 95 & 01 May 96 & -1.68 & -0.81 & -2.01 \\
LW2 & 03 Nov 96 & 17 Sep 96 & -2.63 & -1.34 & -1.95 \\
LW3 & 23 May 97 & 24 Sep 97 & -2.47 & -1.44 & -2.54 \\
LW4 & 11 Oct 97 & 02 Mar 98 & -2.18 & -1.42 & -2.74 \\
LW5 & 14 May 98 & 20 Nov 98 & -2.27 & -0.92 & -2.93 \\
LW6 & 25 Feb 00 & 20 Nov 00 & -2.25 & -0.92 & -3.61 \\
LW7 & 13 Dec 00 & 28 Sep 01 & -2.65 & -0.25 & -3.17 \\
LW8 & 25 Oct 01 & 23 Aug 02 & -3.37 & 0.03 & -4.43 \\
LW9 & 16 Sep 02 & 09 Aug 03 & -5.14 & -0.24 & -7.12 \\
LW10 & 30 Aug 03 & 08 May 04 & -10.32 & -1.56 & -15.75 \\
LW11 & 29 May 04 & 19 Mar 05 & -14.92 & -4.47 & -21.89 \\
LW12 & 02 Apr 05 & 03 Dec 05 & N/A & -9.67 & -11.17 \\
LW13 & 17 Dec 05 & 16 Sep 06 & N/A & -14.01 & N/A \\
LW14 & 30 Sep 06 & 22 Aug 07 & N/A & N/A & N/A \\
LW15A & 10 Sep 07 & 08 Mar 08 & N/A & -33.4 & N/A \\
LW15B & 24 Mar 08 & 25 May 08 & N/A & N/A & N/A \\
LW16 & 15 Jun 08 & 26 Feb 09 & N/A & -31.9 & N/A \\
LW17 & 25 Mar 09 & 08 Oct 09 & N/A & -20.04 & -13.27 \\
LW18 & 03 Nov 09 & 20 Apr 10 & -13.85 & -15.28 & -11.57 \\
\hline & & & & & \\
\hline
\end{tabular}

\section{Conclusion}

The objective of this study was to illustrate the use of InSAR to measure historic ground displacement over the Metropolitan Mine, and demonstrate the advantages of using this technique to identify vertical and horizontal movement vectors. Results provide a detailed review of historic movement occurring between 2006-2010, and patterns of vertical and east-west horizontal ground movement illustrate the timing and spatial extent to which mining activities impacted the ground surface above and surrounding the mine site. A secondary objective was to explore the integration of InSAR results with an existing GPS survey record. In areas where the SqueeSAR results and existing survey data overlapped in time and space, general trends were fairly similar between the two approaches, except along the inner boundary of the identified displacement feature. Subsidence rates were under-estimated in this region due to the rapid and non-linear movement occurring and the characteristics of the radar sensor (low spatial and temporal resolution). The lack of coincident measurement points (i.e. no SqueeSAR measurement points were identified from the same location and time period as the survey lines) prevented a complete calibration from being carried out; however, a simple combination of the two data sets provided a more complete overview of the mine site than either data set alone.

The combination of InSAR and GPS techniques allows for the strengths of both approaches to be exploited, while also serving to compensate weaknesses with either approach. InSAR often provides a dense network 
of points in space, but less so in time (depending on the revisit interval of the satellites), while GPS stations can provide frequent (in the case of permanent GPS stations) and detailed measurements in all three dimensions with much more limited spatial coverage. Therefore, the capability of the SqueeSAR technique to provide information of ground movement over large areas may be beneficial to assess the extent of the area affected by subsidence, to more precisely identify areas where the strongest differential movement is occurring, and to help identify areas of movement that may require higher frequency monitoring with ground-based techniques.

If future monitoring using InSAR were to be carried out over the Metropolitan Mine, several parameters could be modified to address the environment and movement characteristics of this area. For instance, the use of radar satellites with a higher re-visitation frequency and finer pixel resolution compared to the archive imagery used in this historical study would likely result in the identification of a greater density of measurement points, including those with higher displacement rates over a larger portion of the mine (such as the Cosmo-SkyMed and TerraSAR-X satellites which have pixel resolutions of $3 \times 3 \mathrm{~m}$ and can acquire one new image every four and eleven days on average, respectively). The installation of ground-based ARs could be used to measure displacement over specific areas of interest exhibiting low coherence, and if placed near an existing survey line would aid in the integration and cross-validation of GPS and InSAR data.

\section{Acknowledgement}

The project was funded through the research grant (SRG2012/A1) from the School of Mining Engineering, The University of New South Wales. Greg Tarrant (technical services manager) and Andrew Carter (mine surveyor) at Metropolitan Coal Pty Ltd are acknowledged for providing the access to the site and extending the ground survey data. Thanks to Chengguo Zhang (PhD student) of The University of New South Wales for his help in identification of the ground conditions.

\section{References}

Anderson, L., Patterson, D. and Nicholson, M. (2007) Measuring Mine Subsidence - BHP Billiton Illawarra Coal's Diversified Approach, in Proceeding Seventh Triennial Conference on Mine Subsidence : A Community Issue, University of Wollongong, 26-27 November, Newcastle, Australia, Mine Subsidence Technological Society, pp. 53-67.

Bock, Y., Wdowinski, S., Ferretti, A., Novali, F. and Fumagali, A. (2012) Recent subsidence of the Venice Lagoon from continuous GPS and interferometric synthetic aperture radar, Geochemistry Geophysics Geosystems, Vol. 13, pp. 1-13.

Carnec, C. and Delacourt, C. (2000) Three years of mining subsidence monitored by SAR interferometry, near Gardanne, France, Journal of Applied Geophysics, Vol. 43, pp. 43-54.

Chang, H., Ge, L., Ng, A., Rizos, C., Wang, H. and Omura, M. (2008) Combination of Multiple Repeat Orbits of ENVISAT for Mining Deformation Monitoring, Observing our Changing Earth, Springer, pp. 631-637.

Colesanti, C., Ferretti, A., Prati, C. and Rocca, F. (2003) Monitoring landslides and tectonic motions with the Permanent Scatterers Technique, Engineering Geology, Vol. 68, pp. 3-14.

Droz, P., Fumagalli, A., Novali, F. and Young, B. (2008) GPS and InSAR Technologies: A Joint Approach for the Safety of Lake Sarez, in Proceedings 4th Canadian Conference on Geohazards: From Causes to Management, J. Locat, D. Perret, D. Turmel, D. Demers, and S. Leroueil (eds), 20-24 May, Laval, Quebec, Canada, Geological Association of Canada.

Ferretti, A., Prati, C. and Rocca, F. (2001) Permanent Scatterers in SAR interferometry, IEEE Transactions on Geoscience and Remote Sensing, Vol. 39, pp. 8-20.

Ferretti, A., Savio, G., Barzaghi, R., Borghi, A., Musazzi, S., Novali, F., Prati, C. and Rocca, F. (2007) Submillimeter accuracy of InSAR time series: Experimental validation, IEEE Transactions on Geoscience and Remote Sensing, Vol. 45, pp. 1142-1153.

Ferretti, A., Fumagalli, A., Novali, F., Prati, C., Rocca, F. and Rucci, A. (2011a) A new algorithm for processing interferometric data-stacks: SqueeSAR ${ }^{\text {TM }}$, IEEE Transactions on Geoscience and Remote Sensing, Vol. 99, pp. 1-11.

Ferretti, A., Tamburini, A., Novali, F., Fumagali, A., Falorni, G. and Rucci, A. (2011b) Impact of high resolution radar imagery on reservoir monitoring, Energy Procedia, Vol. 4, pp. 3465-3471.

Gao, J., Ge, D., Wu, L., Yin, Z., Deng, Z., Wang, Y., Liao, M. and Zhang, L. (2005) A coherence estimation method for multi-temporal D-InSAR deformation monitoring in coal mining areas, in Proceedings SPIE 6043, MIPPR 2005: SAR and Multispectral Image Processing, 60432S, 3 November, pp. 1-13.

Jarosz, A. and Wanke, D. (2003) Use of InSAR for monitoring of mining deformations, in Proceedings SP-550 FRINGE 2003 ESA International Workshop on ERS SAR Interferometry, 1-5 December, Frascati, Italy.

Jarosz, A., Zahiri, H., Warren, M. and Sowter, A. (2008) Utilisation of InSAR for subsidence monitoring over the caving zone of underground metalliferous mine, in Proceedings Fringe 2007 Workshop, 26 November 2007, Frascati, Italy, viewed 29 October 2010, http://earth.esa.int/workshops/fringe07/. 
Kay, D. (1991) Effects of Subsidence on Steep Topography and Cliff Lines, NERDDP Report Number 1446, NSW Department of Minerals \& Energy, Sydney, $126 \mathrm{p}$.

Klemm, H., Quseimi, I., Novali, F., Ferretti, A. and Tamburini, A. (2010) Monitoring horizontal and vertical surface deformation over a hydrocarbon reservoir by PSInSAR ${ }^{\mathrm{TM}}$, First Break, Vol. 28, pp. 29-37.

Mills, K.W. (2001) Observations of Horizontal Subsidence Movements at Baal Bone Colliery, in Proceedings 5th Triennial Conference of the Mine Subsidence Technological Society - Current Practice and Issues, Maitland, Australia, pp. 99-112.

Mills, K.W. (2011) Effect of Surface Topography on Mining Subsidence damage to River Channels, ACARP Project C15025.

Mills, K.W., Morphew, R.H. and Crook, R.J. (2011) Experience of Monitoring Subsidence at Ulan Coal Mine, in Proceedings 8th Triennial Conference of the Mine Subsidence Technological Society, Pokolbin, Australia.

Ng, A.H-M., Chang, H-C., Ge, L., Rizos, C. and Omura, M. (2008) Assessment of radar interferometry performance for ground subsidence monitoring due to underground mining, Earth Planets Space, Vol. 60, pp. 1-14.

Perski, Z., Hanssen, R., Wojcik, A. and Wojciechowski, T. (2009) InSAR analyses of terrain deformation near the Wieliczka Salt Mine, Poland, Engineering Geology, Vol. 106, pp. 58-67.

Raucoules, D., Le Mouelic, S., Carnec, C. and Guise, Y. (2008) Monitoring post-mining subsidence in the Nord-Pas-de-Calais coal basin (France): comparison between interferometric SAR results and levelling, Geocarto International, Vol. 23, pp. $287-295$.

Tamburini, A., Del Conte, S., Larini, G., Lopardo, L., Malaguti, C. and Vescovi, P. (2013) Application of SqueeSAR ${ }^{\mathrm{TM}}$ to the characterization of deep seated gravitational slope deformation: the Berceto case study (Parma, Italy), Landslide Science and Practice, C. Margottini, P. Canuti, K. Sassa (eds), Springer, pp. 437-443.

Wegmüller, U., Werner, C., Strozzi, T. and Wiesmann, A. (2004) Monitoring mining induced surface deformation, in Proceedings 25th Geoscience and Remote Sensing Symposium, Seoul, Korea, 25-29 July, pp. 2165-2168.

Yue, H., Liu, G., Guo, H., Li, X., Kang, Z., Wang, R. and Zhong, X. (2011) Coal mining induced land subsidence monitoring using multiband spaceborne differential interferometric synthetic aperture radar data, Journal of Applied Remote Sensing, Vol. 5(1), pp. 053518-053518-14. 